\title{
Stapler Haemorroidopexy - our experience in a tertiary care hospital of central India
}

\author{
Rakhonde AK ${ }^{1}$, Chanchalani $\mathbf{R}^{2}$ \\ ${ }^{1}$ Dr. Anant Kumar Rakhonde, Associate Professor, Department of surgery, Chirayu Medical College and hospital, \\ Bhopal, ${ }^{2}$ Dr. Roshan Chanchalani, Associate Professor, Department of surgery, Chirayu Medical College and hospital, \\ Bhopal, MP, India
}

Address for Correspondence: Anant Kumar Rakhonde, Email- arakhonde1@ gmail.com.

Background: Symptomatic haemorroids poses a very big issue on the public health. Treatment options for haemorroids is surgery for $2^{\text {nd }}, 3^{\text {rd }}, 4^{\text {th }}$ degree haemorroids, but due to fear of surgery due to pain patients usually tries to avoid it and later on comes with complications which in turn adds for increased morbidity and mortality. Since stapler haemorroidopexy is claimed to be superior than other available procedures for heamorroids the study is undertaken to evaluate the efficacy in terms of operation time, post-operative pain, hospital stay, return to normal activity and return to work, relapse of symptoms, recurrence and patient satisfaction. Material and Methods: The Study was done using a circular stapling device for the treatment of Symptomatic haemorrhoids grade 2, 3 and 4 over a period from November 2011 to December 2014 for age group between 22 to 78 yrs of age. Observations: Total 88 patientswith symptomatic haemorroids who agreed for treatment with stapler surgery for haemorroids were operated. Operative time ranged between 55- 20 min.with mean operative time $36.44 \mathrm{~min}$. Post-op pain measured using Visual analogue scale after aprox. $24 \mathrm{hrs}$ and is in the range of mild pain(0-2) in 82 (93.18\%) patients. Post-operative pain: In $4(4.54 \%)$ patients were having VAS between 2-4 and required injection diclofenac sodium analgesic to be added for pain in the regime. 2 patients $(2.27 \%$ ) complaints of unbearable pain and opioid analgesic has to be added in such cases but for 2 days. Mean hospital stay ranges between $23 \mathrm{hrs}-80 \mathrm{hrs}$. All the 82 patients $(93.18 \%)$ patients returned to normal activity within $4-5$ days and joined their respective field of work within 7-8 days. Conclusion: Stapler haemorroidopexy is a good alternative to the open surgery for the treatment of $2^{\text {nd }}, 3^{\text {rd }}$, and $4^{\text {th }}$ degrees haemorrhoids in terms of less pain, early return to normal activities, faster return to work, but high cost of instrument puts the procedure to back foot.

Key words: Stapler Haemorroidopexy, haemorrhoids, Symptomatic haemorrhoids

\section{Introduction}

Hemorrhoids are "anal cushions" which assist in continence of air and liquid by providing a final seal in the anal canal The typical "angio-cavernous structure" controls blood volume regulation, which increases and decreases the size of the hemorrhoids. The emptying and filling is believed to be controlled by receptors which detect the presences of gas and liquid in the anal canal [1].

Due to degenerative changes with old age, the connective tissue (also k/a Suspensory ligaments of parks) supporting these anal cushions becomes loose and lax resulting in their descent and prolapsed .Other predisposing factors which contributes to the prolapse are faulty life style, dietary habits, faulty bowel habits,

Manuscript received: $16^{\text {th }}$ June 2015

Reviewed: $24^{\text {th }}$ June 2015

Author Corrected: $4^{\text {th }}$ July 2015

Accepted for Publication: 20 $0^{\text {th }}$ July 2015 chronic straining at stools, chronic constipation, diarrhoea, purgative abuse, increased intra-abdominal pressure etc. leads to formation of haemorroids.

Anal cushions are present at 3'o, 7,o and 11,o clock position these are known as primary haemorroidsand are related to the branches of superior haemorroidalvessels.Sometimes in between these primary haemorroids there may be dilatation and prolapsed of anal mucosa forming secondary haemorroids. Haemorroids are also classified as Internal Hemorrhoids: Develop within the anus beneath the mucosa above the dentate line. Sometimes, an internal hemorrhoid may stretch until it bulges outside the anus. This is called a prolapsed hemorrhoid.

External Hemorrhoid [2] Develop below the dentate line, near the anus and are covered by very thin 
sensitive skin sometimes caused due to inflammation of peri anal glands or constipation. If a blood clot develops in one of them, a painful swelling may occur which is known as peri anal hematoma.

Haemorroids are also classified according to Degree [1]

- $\mathbf{1}^{\text {st }}$ Degree

(Bleeding without prolapse)

- $2^{\text {nd }}$ Degree

(Prolapse with spontaneous reduction)

- $3^{\text {rd }}$ Degree

(Prolapse with manual reduction)

- $4^{\text {th }}$ Degree

(Irreducible Prolapse)

\section{Material}

The prospective study was done inChirayu Medical College and Hospital from November 2011 to December 2014 for age group between 22 to 78 yrs of age. Both males and females patients were taken into consideration. In total 88 patients were operated using stapler.

Inclusion Criteria: All the symptomatic patients suffering from Grade 2,3 and 4 haemmorroids and consented for surgery by this method.

Exclusion criteria: Grade 1 haemorroids, asymptomatic haemorroids, Thrombosed haemorroids, perianal abscess history of previous rectal surgery, haemorroidsduring pregnancy, patients with coagulation disorder

\section{Methods}

The Study was conducted using a circular stapling device for the treatment of Symptomatic haemorrhoids (grade 2,3 and 4) (Ethicon PPH03 and Coviedien stapler) for surgery. Clearance is taken from the ethical committee. After careful selection of patients, routine investigations and pre anaesthetics check-up was done. The patient is scheduled for surgery under spinal anaesthesia and is given lithotomy position. Enema was given in the morning and ensured that the patient has passed bowel before surgery. Injection ceftriaxone $1 \mathrm{gm}$. i.v. is given before surgery. Procedure: The prolapse if any is reduced. The anal verge is gently massaged and dilated before inserting the circular anal dilator.The circular anal dilator with the obturator in place is inserted and the obturator is removed.The anal dilator is secured to the skin with silk sutures. The dentate line identified. The transparent circular anal dilator allows easy introduction of the instrumentation, view of dentate line, and protection of the internal sphincter and dentate line. The Purse-String Suture Anoscope is introduced through the dilator. The circumferential purse-string is placed at the correct height (at the tip of the anoscope) and depth (only mucosa and submucosa). After each stitch the Purse-string Suture Anoscope is extracted, then rotated and inserted again.The purse string sutures are placed close together (6-10 small bites) to allow better traction of the mucosal prolapse. 2.0 prolene is used for taking purse string. The Hemorrhoidal Circular Stapler is fully opened prior to insertion through the dilator. The anvil is positioned beyond the purse-string which is tied onto the rod with a throw-knot.Using the Suture Threader the tails of the purse-string are drawn down through the lateral channels of the stapler. Moderate traction on the pursestring when inserting the stapler draws the mucosal prolapse into the casing of the stapler. The stapler is closed all the way downto ensure the staples are compressed enough to provide the tightest staple line. In females, check the vagina to ensure that the posterior vagina wall is not incorporated in the staple line. It is recommended to wait 30 seconds before firing and approximately 30 seconds after firing. Stapler is removed. Anoscope is reinserted for careful inspection of staple line and application of stitches on any bleeders if necessary.Packing the anal canal is not recommended but we are routinely packing the anal canal with pack soaked in xylocaine jelly and povidone iodine to improve hemostasis and to reduce post op pain. Doughnut ischecked for any muscle layer removed accidently and to confirm that only mucosa and submucosa is included in the purse string. Routinely doughnut removed is sent for H-P Examination to see for any muscle fibres. External hemorrhoids were not touched and are explained to the patient during counseling and patient empowerment before surgery. All doughnuts removed were sent for histo-pathological exam. Out of $88,8(9.09 \%)$ were showing thin rim of muscle also along with mucosa and submucosa. No other significant abnormality was seen \& rest 80 $(90.91 \%)$ were showing only rectal mucosa and sub mucosa.

Patients were started with fluids orally gradually encouraging to soft diet within 4-6 hours following surgery.when the patient gained consciousness and when the effect of spinal anesthesia has gone, Pain scores were noted down using VAS (visual analogue 
scale) at 6-8 hrs of surgery. As a protocol a single dose of i.v.paracetamol (1gm.) infusion is given at the end of procedureand is repeated on SOS basis. If VAS score is more than 2 injection diclofenac sodium $75 \mathrm{mg}$ is added and pain control is noted. The patient is given injection tramadol if VAS is more than 4 or pain not controlled by either of above two. The patient is discharged when painfree and passed motions. Every patient is prescribed laxative in the post operative period for approximately a month. Patients were followed up on day $7,15,30^{\text {th }}$ and 6months. $83(94.31 \%)$ patients gave relief of symptoms within 3 to 4 weeks following surgery and 5 patients $(5.69 \%)$ had relieved upto 6 weeks. 2 patients complained of bleeding at -3 months following surgery which was managed conservatively by laxative. At 6 months follow up, $82(93.18 \%)$ patients are satisfied, 4 patients $(4.54 \%)$ are partially satisfied.and 2 patients $(2.27 \%)$ patients are un-satisfied, which has raised to 84 $(95.45 \%)$ at one year. The foremost cause of dissatisfaction is more cost of the stapling device and misconceptions of the patient regarding the procedure.

\section{Results}

Total 88 patientswith symptomatic haemorroids who agreed for treatment with stapler surgery for haemorroids were operated. Out of which $62(70.45 \%)$ were males and 26 were females $(29.54 \%)$. Most common complaint was bleeding PR seen in $(90 \%)$ of cases followed by constipation $60 \%$ and prolapsed (something coming out or felt at anus) $43 \%$. Operative time ranged between 55- 20 min with mean operative time 36.44 min.post-op pain measured using Visual analogue scale after aprox. $24 \mathrm{hrs}$ and is in the range of mild pain(0-2) in $82(93.18 \%)$ patients. Post-operative pain-In $4(4.54 \%)$ patients were having VAS between 2-4 and required injection diclofenac sodium analgesic to be added for pain in the regime. 2 patients $(2.27 \%)$ complaints of unbearable pain and opioid analgesic has to be added in such cases but for 2 days. Mean hospital stay ranges between $23 \mathrm{hrs}-80 \mathrm{hrs}$. 81patients $(92.04 \%)$ were discharged within 24 hrs of surgery, 5 patients $(5.68 \%)$ were discharged within $36-40 \mathrm{hrs}$. and 2 patients $(2.27 \%)$ required $72-80$ hrs of hospitalization.
All the 82 patients (93.18\%) patients returned to normal activitywithin 4-5 days and joined their respective field of work within 7-8 days. All the patients were followed up on $7^{\text {th }}$ day, $15^{\text {th }}$ day and 1 and half month, 6 months and 1 year.

\section{Discussion}

The earliest reference ofhaemorroids dates back to Egyptian papyri of $1700 \mathrm{BC}$ and the first surgical treatment described in the Hippocratic Treatises of 460 BC [3]. Haemorroids and piles terms are used synonymously and interchangeably, collectively it is referred as "Haemoirroidal disease" [4]. Open haemorroidectomy (Milligan Morgan and Ferguson techniques) has been accepted world wide as thebest choice for treatment of symptomatic haemorroids $[5,6,7]$. Although the technique is safe and effective it is associated with much post operative pain and due to this very reasonthe technique is not wellaccepted by the patients and different approaches have been advocated from time to time [8,9]. Stapler haemorroidectomy was introduced in 1993 as an alternative to traditional methods of operative treatment of symptomatic haemorroidsand is refined and practiced by Antonio Longo [10]. In this method excision of a strip of mucosa and submucosa done in the rectum above dentate line and is re-anastamosed using a circular stapling device.The procedure is claimed to be associated with less morbidity, less postoperative pain, earlier return to normal activities but requires skill to perform and still under study to be accepted for widespread use. So many studies were done on the treatment of haemorroids and were published from time to time.

Shalaby and Desoky et al in 2001 [11] reported a mean age group of 44 years with a male to female ratio of $3: 2$ .maximum patients had grade 4 haemorroids. Similarly other researchers also gave there results which is summarized in the table. And in which our results can be comparable to any national or international studies.

Operating Time- The mean operating time was reported and analysed in various trials $, 12,13,14,15,16,17,18,19,20,21,22]$. 
Table showing operating times by different authors

\begin{tabular}{|l|l|}
\hline Study / Authors & Operating Time in minutes \\
\hline Rowsell et al, 2000 [15] & 35 \\
\hline Shalaby and Desoky ,2001 [11] & 9 \\
\hline Gravie et al 2005 [13] & 21 \\
\hline Bharti et al,2012 [24] & 29 \\
\hline R Gajbhiye et al, 2014 [25] & 31.76 \\
\hline Present study & 32.4 \\
\hline
\end{tabular}

Studies have shown the difference in time taken for the procedure and our results are comparable with the other studies.[11,15,23,24,25].

Post-operative pain- Postoperatively pain was scored on visual analogue scale, 0 indicating no pain and 10 severe pain. The pain score for stapled haemorroidectomy was significantly lower. The pain score noted was 2.5 by Rowsell et al and Shalaby and Desoky [11,15] and 2.31 by R Gajbhiye et al [25]. In our study, $93.19 \%$ pts. Showed the pain score between 0-2. In 4 (4.54\%)patients were having VAS between 2-4 and required injection diclofenac sodium analgesic to be added for pain in the regime. 2 patients $(2.27 \%)$ complaints of unbearable pain and opioid analgesic has to be added in such cases but for 2 days $[11,15,25]$.

Length of Hospital Stay- Data for mean hospital stay was studied from world literature and compared, showed a shorter hospital stay for stapler haemorroidopexy $[11,12,13,14,16,15,19,25]$.

\begin{tabular}{|l|l|l|l|}
\hline \multicolumn{1}{|c|}{ Study } & \multicolumn{1}{|c|}{ Operating Time } & \multicolumn{1}{c|}{$\begin{array}{c}\text { Mean Hospital } \\
\text { Stay(days) }\end{array}$} & \multicolumn{1}{|c|}{ Return to work (days) } \\
\hline Rowsell et al (2000) & 35 & 1.09 & 18 \\
\hline $\begin{array}{l}\text { Shalaby and Desoky } \\
(2001)\end{array}$ & 9 & 1.45 & 8.2 \\
\hline Gravie et al (2005) & 21 & 2.2 & 8 \\
\hline Bharti et al (2012) & 29 & 2.7 & 8.3 \\
\hline R Gajbhiye et al (2014) & 31.76 & 1.45 & 8 \\
\hline Present study & 32.4 & 1.02 & \\
\hline
\end{tabular}

Table shows difference in mean hospital stay as depicted in different studies, overall it is less for stapler haemorroidopexy. Mean hospital stay in the present study is comparable with the other studies and is least 1.02 days which is 1.09 days, 1.45 days, 2.3 days, 2.7 days, 2.7 days, 1.45 days respectively.[11,13,16, 22,23].

\section{Return to normal activities}

\begin{tabular}{|l|l|l|l|}
\hline Study & Operating Time & Mean Hospital Stay(days) & Return to work (days) \\
\hline Rowsell et al (2000) & 35 & 1.09 & 18 \\
\hline Shalaby and Desoky (2001) & 9 & 1.45 & 8.2 \\
\hline Bharti et al (2012) & 29 & 2.7 & 8 \\
\hline R Gajbhiye et al (2014) & 31.76 & 1.45 & 8.3 \\
\hline Present study & 32.4 & 1.02 & 8 \\
\hline
\end{tabular}

Table shows that the mean time for return to normal activities and resuming of work was studied. it is maximum 18 days [15] and is 8,8.2,8.3which is comparable with present study [11,24,25].

Relapse of symptoms- 16 patients $(18.18 \%)$ reported minor bleeding due to non following of strict dietary advice and to avoid constipation however these pts. are relieved after laxatives and no intervention is required. 
Recurrence- Recurrent bleeding and recurrent prolapse are the most common complaints. Recurrent prolapse rate was mentioned in studies at mean 15.9 months to be $11 \%$ [22,26]. In our series 1 patient $(1.136 \%)$ showed mucosal prolapsed with one small $2^{\text {nd }}$ degree haemorroid after 4 and half years of surgery due to some personnel and social issues as unable to follow dietary advise, avoidance of constipation and life style changes.

\section{Patient Satisfaction}

Various studies has reported patients satisfaction to be $89 \%$ [24, 26,]. Despite recurrence the patients were satisfied because of less severity of symptoms than presentation [27].

In our series, $82(93.18 \%)$ patients are satisfied, 4 patients $(4.54 \%)$ are partially satisfied.and 2 patients $(2.27 \%)$ patients are un-satisfied. The foremost cause of dissatisfaction is more cost of the stapling device.

\section{Conclusion}

Stapler haemorroidopexy is a good alternative to the open surgery for the treatment of $2^{\text {nd }}, 3^{\text {rd }}$, and $4^{\text {th }}$ degrees haemorroids in terms of less pain, early return to normal activities, faster return to work, but high cost of instrument puts the procedure to backfoot. The procedure is easy to master reproducible and gives constant results to surgical skills although associated with some complications which can be avoided by good training of surgeon, cautious patient selection and good counseling of patients, gives feel good results.

\section{Funding: Nil \\ Conflict of interest: Nil \\ Permission from IRB: Yes}

\section{References}

1. Zeitoun JD, de Parades V. Haemorrhoidal disease: from pathophysiology to clinical presentation]. Presse Med. 2011 Oct;40(10):920-6. doi: 10.1016/j.lpm.2011.06.017. Epub 2011 Aug 6. French.

2. Owais AE, Sumrien H, Mabey K, McCarthy K, Greenslade GL, Dixon AR. Laparoscopic ventral mesh rectopexy in male patients with internal or external rectal prolapse. Colorectal Dis. 2014 Dec;16(12):995-1000. doi: 10.1111/codi.12763.

3. Parks A G : De Haemorroids : A study in surgical history. Guys Hosp Resp 1995; 104: 135-156

4. Loder P B, Kamm M A, Nicholls R J, et al. Haemorroids: Pathology, Pathophysiology and Etiology. Br J Surg. 1994;81: 946-954.

5. Lorenzo-Rivero S (August 2009). Haemorroids: diagnosis and current management. Am Surg 75 (8) : 635-42.
6. Milligan ET, Morgan CN, Jones LE et al: Surgical anatomy of the anal canal and operative treatment of haemorroids. Lancet 1937; 1119-1124.

7. Ferguson JA, Heaton JR: Closed haemorroidectomy. Dis colon rectum 1959; 2: 1176-79.

8. Thompson WHF. The nature of haemorroids. Br J Surg 1975; 62: 542-52.

9. The Standard Task Force. American Society of Colon and Rectal Surgeons. Practice parameters for the treatment of haemorroids. Dis Colon rectum 1993; 36: 1118-20.

10. Longo A. Treatment of haemorroid disease by reduction of mucosa and haemorroid prolapsed with a circular suturing device. A new procedure. Proceedings of the sixth World Congress of Endoscopic Surgery, Rome, Italy,3-6 June1998,pp 777-784.

11. Shalaby R, Desoky A randomized clinical trial of stapled versus Milligan-Morgan Haemoirroidectomy. Br. J. Surg2001, 88; 1049-53.

12. Boccasanta P, CaprettiP G ,Venturi $M$ et al. Randomized controlled trial between stapled circumferential mucosectomy and conventional circular haemorroidectomy in advanced haemorroids with external mucosal prolapsed. Am J Surg 2001; 182: 6468.

13. Gravie JF, Lehur P A, Huten N et al. Stapled haemorroidopexy versus Miligan-Morgan Haemorroidectomy; a prospective randomized, multicenter trial with 2 years prospective follow up. Ann Surg 2005; 242: 29-35. 
14. Pavlidis T, Papaziogas B, Souparis A et al. Modern stapled Longo procedure vs conventional MilliganMorgan Haemorroidectomy : a randomized controlled trial. Intl J Colorectal Diseases 2002; 17: 50-53.

15. Rowsell M, Bello M, Hemingway DM. Circumferential Mucosectomy (staple haemorroidectomy) vs conventional haemorroidectomy: randomized controlled trial. Lancet 2000; 355: 779-81.

16. Racalbuto A, Aliotta I , Corsaro G et al. Haemorroidal stapler prolapsectomy vs MilliganMorgan Haemorroidectomy . a long term randomized trial. Intl J Colorectal Disease 2004; 19: 239-44.

17. Chung CC, Cheung HYS, Chan ESW et al. Stapled haemorroidopexy vs Harmonic scalpel haemorroidectomy. A randomized trial. Dis Colon Rectum 2005; 48: 1213-1219.

18. Ho Yh, Cheong WK, Tsang C, et al. Stapled haemorroidectomy - cost effectiveness. Randomized controlled trial including incointenence scoring, anaorectalmanometry and endoanal ultrasound assessment upto three months. Dis Colon Rectum 2000; 43: 1666-75.

19. Bikhchandani J, Agarwal PN, Hant R, et al. Randomized controlled trial to compare the early and midterm results of stapled vs open haemorroidectomy . Am J urg 2005; 189: 56-60.

20. Basdanis G, Papadopoulus VN, Michaelopoulus A, et al. Randomized clinical trial of stapled haemorroidectomy vs open with Ligasure for prolapsed piles. Surg Endosc 2005; 19: 235-39.
21. Correa- Rovelo JM, Tellez O, Obregon L, et al. Stapled rectal mucosectomy vs Closed haemorroidectomy: a randomized clinical trial. Dis Colon Rectum 2002 ; 45: 1367-74.

22. W. J. Shao, G.C. H. Li, Z.H. K. Zhang, et al. Systematic rewiew and metaanalysis of randomized controlled trials comparing stapled haemorroidopexy with conventional haemorroidectomy.Br J Surg 2008; 95: 147-60.

23. Gouda M ,Ellaben, Stapled haemorroidectomy vs Traditional haemorroidectomy for the treatment of haemorroids. World J Surg vol.2 issue 2010.

24. Bharati Hiremath , Gupta S. Stapled haemorroidopexy for haemorroids. A review of our early experience. Ind. J. Surg 2012; 74(2): 163-5

25. R. Gajbhiye, B.Tirupade, H. Banarkaretal. Prospective study of stapler haemorroidectomy. JEMDS 2014; vol.3: issue73: p. 15356-363.

26. Ammaturo C, Tufano A. Stapled heamorroidopexy vs milligan morgan haemorroidectomy for grade 3 haemorroids: a randomized clinical trial G Chir; 2012: 33(10): 346-351.

27. Wolthius AM, Pennincks F, Cornille JB, et al. Recurrent symptoms after stapled haemorroidopexy and the impact on patients satisfaction after a minimal of two years follow up. Acta Chir Belg; 2012; 112(6): 419-22.

\section{How to cite this article?}

Rakhonde AK, Chanchalani R. Stapler Haemorroidopexy - our experience in a tertiary care hospital of central India. Int $J$ Med Res Rev 2015;3(6):635-640. doi: 10.17511/ijmrr.2015.i6.123. 